\title{
Erratum to: Medical Rapid Response in Psychiatry: Reasons for Activation and Immediate Outcome
}

\author{
Peter Manu ${ }^{1,2,3}$ - Kristy Loewenstein ${ }^{1,4}$ - Yankel J. Girshman ${ }^{1}$ • \\ Padam Bhatia ${ }^{1} \cdot$ Maira Barnes $^{1} \cdot$ Joseph Whelan $^{1}$. \\ Victoria A. Solderitch ${ }^{5} \cdot$ Liliana Rogozea $^{6} \cdot$ Marybeth McManus $^{1}$
}

(C) Springer Science+Business Media New York 2015

\section{Erratum to: Psychiatr Q DOI 10.1007/s11126-015-9356-4}

The following corrections to author information should be noted:

Kristy Loewenstein, MS, RN-BC, PMHNP-BC is Director of Nursing Education and Professional Development.

Joseph Whelan, MBA, RN is Director of Patient Care Services.

Maira Barnes, MS, RN-BC, CNE is Nurse Educator.

Marybeth McManus, MPA, BSN, RN-BC is the Chief Nursing Officer and Associate Executive Director of Patient Care Services.

The online version of the original article can be found under doi:10.1007/s11126-015-9356-4.

Peter Manu

pmanu@nshs.edu

1 Patient Care Services, Zucker Hillside Hospital, North Shore - LIJ Health System, 75-59 263rd Street, Glen Oaks, NY 11004, USA

2 Hofstra North Shore - Long Island Jewish School of Medicine at Hofstra University, Hempstead, NY, USA

3 Albert Einstein College of Medicine, Bronx, NY, USA

4 Adelphi University College of Nursing and Public Health, Garden City, USA

5 Long Island Jewish Medical Center, New Hyde Park, NY, USA

6 Transilvania University, Brasov, Romania 